\title{
Synthesis of (+)-Cortistatin A
}

Key words

\section{cortistatin A}

Mukaiyama

hydration

remote

functionalization

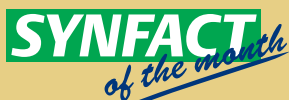

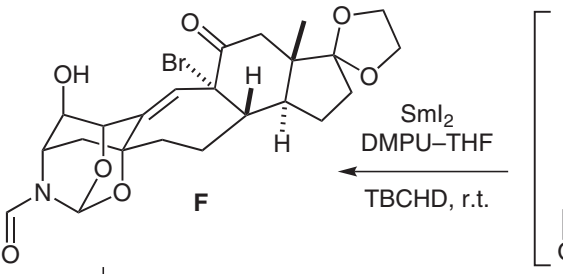

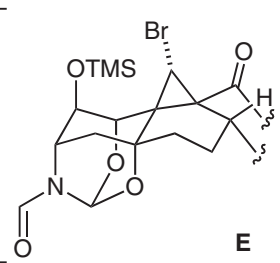

$\mathrm{Co}(\mathrm{acac})_{2}, \mathrm{PhSiH}_{3}, \mathrm{O}_{2}$

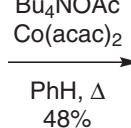<smiles>CCC1CCC2C1CCC1=C[C@H](NC=O)C(OC(C)=O)[C@H](C)[C@@]12C</smiles>
$\underset{\text { then } \mathrm{TsOH} \cdot \mathrm{H}_{2} \mathrm{O}}{\mathrm{K}} \mathrm{CO}_{3}, \mathrm{MeOH}$, r.t.
$65 \%$
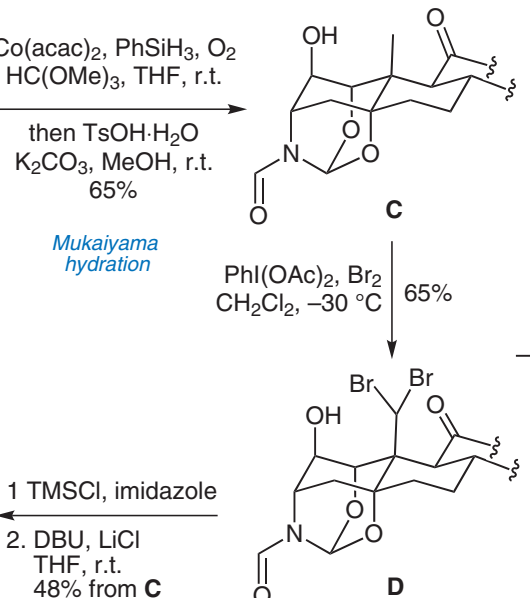

Significance: (+)-Cortistatin A inhibits the proliferation of human umbilical vein endothelial cells (HUVECs, $I_{50}=1.8 \mathrm{nM}$ ) without showing any toxicity. This synthesis utilizes a novel hydroxyldirected dibromination of a methyl group $(\mathbf{C} \rightarrow \mathbf{D})$ using $\mathrm{AcOBr}$ generated in situ.
Comment: Dibromination was achieved by a $\mathrm{S}_{\mathrm{H}} 2$ reaction of the transient $\mathrm{O}$-centered radical

$(\mathbf{C} \rightarrow \mathbf{J} \rightarrow \mathbf{K} \rightarrow \mathbf{D})$. A Sml 2 -mediated radical opening of the cyclopropane $\mathbf{E}$ led to the formation of a dienolate via intermediates $\mathbf{L}$ and $\mathbf{M}$, which then reacted with $\mathrm{TBCHD}$ to give the $\alpha$-bromoketone $\mathbf{F}$.

SYNFACTS Contributors: Philip Kocienski, Indu Dager 